\title{
LUNG VOLUME REDUCTION SURGERY: AN OVERVIEW
}

Rodrigo Afonso da Silva Sardenberg ${ }^{1 *}$, Riad Naim Younes ${ }^{2}$, Daniel Deheizelin ${ }^{3}$

Study conducted at Hospital AC Camargo and Hospital Sírio Libanes, São Paulo, SP

\author{
*Correspondence: \\ Alameda Ribeirão Preto, 438 \\ Apto. 1503 - Bela Vista \\ São Paulo - SP \\ CEP: 01331-000
}

\begin{abstract}
SUMMARY
This study intends to review the literature on the efficacy, safety and feasibility of lung volume reduction surgery (LVRS) in patients with advanced emphysema. Studies on LVRS from January 1995 to December 2009 were included by using Pubmed (MEDLINE) and Cochrane Library literature in English. Search words such as lung volume reduction surgery or lung reduction surgery, pneumoplasty or reduction pneumoplasty, COPD or chronic obstructive pulmonary disease and surgery, were used. We also compared medical therapy and surgical technique. Studies consisting of randomized controlled trials, controlled clinical trials (randomized and nonrandomized), reviews and case series were analyzed. Questions regarding validity of the early clinical reports, incomplete follow-up bias, selection criteria and survival, confounded the interpretation of clinical data on LVRS. Patients with upper, lower and diffuse distribution of emphysema were included; we also analyzed as key points perioperative morbidity and mortality and lung function measurement as FEV1. Bullous emphysema was excluded from this review. Surgical approach included median sternotomy, unilateral or bilateral thoracotomy, and videothoracoscopy with stapled or laser ablation. Results of prospective randomized trials between medical management and LVRS are essential before final assessment can be established.
\end{abstract}

KEY WORDS: Thoracic surgery. Thoracic surgery, video-assisted. Pulmonary emphysema. Pulmonary disease, Chronic obstructive. Video-assisted surgery.

\section{INTRODUCTION}

Lung volume reduction surgery (LVRS) continues to be one of the most controversial cardiothoracic procedures in recent years. The report by Cooper et al. ${ }^{1}$ in 1995 showing the benefits from lung volume reduction surgery by improving pulmonary function, was y rapidly disseminated throughout the United States and the world. It modified the approach of Brantigan and Mueller ${ }^{2}$ by using a median sternotomy , thus allowing access to both lungs and used a buttressed staple excision technique. The idea was then to remove the hyperinflated and functionless "target areas" resulting in improvement of the remaining lung.

During early experience with LVRS, functional results, operative mortality as well as morbidity were highly variable. Questions regarding t validity of the early clinical reports, incomplete follow-up bias, selection criteria and survival, confounded the interpretation of clinical data onLVRS. Some authors further cited high surgical mortality rate, prolonged mechanical ventilation and hospital stay of some patients ${ }^{2}$. These early observations permitted a claim that one-year mortality after LVRS reaches around 23\%, with the uncertainty of whether this number disclosed the expected results of a natural history, or these numbers were under-represented by the centers that performed such procedures since they did not publish their outcomes.
For obstructive lung disease, medical therapy contimnues to be the mainstay of treatment and the major steps are smoking cessation, pulmonary rehabilitation, bronchodilator therapy and oxygen supplementation, whenever indicated.

There is some disparity in published reports on patient selection criteria as well as on outcomes for patients submitted to LVRS. Data outlining success predominates over some reports of failure but it seems to be an unclear conclusion about this new technique ${ }^{3}$.

The purpose of this report is to describe the outcomes of various types of LVRS and also to analyze the current safety and efficacy of this surgical procedure.

\section{Methods}

We conducted a methodological assessment of the literature, where studies published in English were included.

Studies on lung volume reduction surgery were identified using MEDLINE (January 1995 - December 2009) and the Cochrane Library (January 1995- December 2009).

The search words were: lung volume reduction surgery or lung reduction surgery, pneumoplasty or reduction pneumoplasty, LVRS or surgery for emphysema, COPD or chronic obstructive pulmonary disease and surgeryA comparison between medical therapy and surgical technique was made.

1. Doutorado em Medicina - Cirurgião Torácico do AC Camargo, Hospital Sírio Libâanes e Hospital Alemão Oswaldo Cruz, São Paulo, SP

2. Professor Livre-Docente da Universidade de São Paulo - USP e Diretor Clínico e Chefe do Núcleo Avançado de Tórax do Hospital Sírio Libânes, São Paulo, SP

3. Professor Livre-Docente da Universidade de São Paulo - USP - Pneumologista do Hospital Sírio Libânes, São Paulo, SP 
In order to be included in this review, studies consisted of randomized controlled trials, controlled clinical trials (randomized and nonrandomized), reviews and case series. Entry criteria for studies included: perioperative morbidity and mortality; lung function measurement as $\mathrm{FEV}_{1}$; patients with any kind of heterogeneous emphysema (upper, lower or diffuse) while ; bullous emphysema was excluded from this review. The surgical approach included median sternotomy, unilateral or bilateral thoracotomy, and videothoracoscopy with stapled or laser ablation. The authors attempted to view LVRS as a surgical option for patients with severe emphysema - with particular emphasis placed on safety and efficacy aspects of the procedures also offering a critical review of this technique.

Physiopathology of Emphysema - Understanding the Problem This disease, which is part of a spectrum of conditions also known as chronic obstructive pulmonary disease (COPD), is frequent in smoker patients, usually in association with features of chronic bronchitis. Its physiopathology is mainly characterized by airflow obstruction and hyperinsuflation ${ }^{4}$. Briefly, it is defined anatomically by "abnormal, permanent enlargement of airspaces distal to the terminal bronchiole, accompanied by destruction of their walls and without obvious fibrosis"3,4,5. This remodeling of the peripheral lung units produces a decreased elastic recoil pressure ${ }^{6}$. As a result, under static conditions, the emphysematous lung requires less pressure to inflate, but once inflated it exerts less emptying pressure than a normal lung. There is as well, a significant mechanical compromise of the diaphragm (flattened position in chest radioghraphs), resulting in a markedly increased work of breathing?.

The diaphragm dysfunction is a main problem while the disease worsens: affecting chest wall mechanics, resulting in further increase of the work of breathing. Due to its flattened position, a result of over stretch of its fibers, the diaphragm in less capable of generating inspiratory force. As such, the less effective diaphragm work results in fatigue and respiratory failure ${ }^{7}$.

Airway inflammation, bronchospasm and increased secretion also have a role in the increased airway pressure. The clinical consequence is incomplete exhalation with intrinsic positive-end-expiratory pressure (auto-PEEP) or dynamic pulmonary hyperinflation caused by retained gas volume in the lungs ${ }^{5}$.

\section{Medical and Surgical Therapies}

Medical Treatment

The main goal of medical therapy for emphysema patients are to: retard chronic disease progression; treat acute exacerbations; control symptoms and improve quality of life. Medical management includes patient education and risk factor avoidance, by eliminating causative agents (tobacco), prevention of infection, pulmonary toilet, rehabilitation and pharmacologic treatment ${ }^{9}$. Current management of COPD can be divided into pharmacologic and non pharmacologic categories, according to the Global Initiative for Chronic Obstructive Lung Disease 2003 (GOLD 2003) ${ }^{10}$. Pharmacologic treatment include bronchodilators, inhaled corticosteroids, combination therapy and long-term oxygen therapy. Non-pharmacologic therapies include smoking cessation, optimizing nutrition, pulmonary rehabilitation, mechanical ventilation and lung volume reduction surgery (LVRS) for selected cases. Current guidelines recommended inhaled longacting bronchodilators as the main method of therapy. Calverly et al. ${ }^{11}$ performed bronchodilator combination testing in 660 COPD patients classified according to the European Respiratory Criteria (ERS) and the American Thoracic Society (ATS) spirometric parameters and showed that $55 \%$ of patients changed from irreversible to reversible status. Therefore, reduction or elimination of dependence on systemic corticosteroids should be an essential goal of a rehabilitation program. Some authors postulated that randomized trials have failed to show a significant effect of inhaled corticosteroids on pulmonary function ${ }^{24}$, but a meta-analysis by Sutherland ${ }^{12}$ showed that high-dose inhaled corticosteroids reduced decline of $\mathrm{FEV}_{1}$, when compared with placebo.

Cigarette smoking cessation should be the physician's first intervention, especially if there is some indication for surgical treatment. It is the only long-term intervention that shows clear evidence in lung function improvement furthermore it is a demonstration of the patient's commitment to treatment. Supplemental oxygen therapy is the only approach that increases lung function and survival in COPD patients, as shown in randomized trials. Patients with a $\mathrm{PaO}_{2}$ $<55 \mathrm{mmHg}$ or a $\mathrm{SaO}_{2}<88 \%$ should receive supplemental oxygen therapy; if the patient has a $\mathrm{PaO}_{2} 55-59 \mathrm{mmHg}$ or a $\mathrm{SaO}_{2}<89 \%$ with signs of pulmonary hypertension or cor pulmonale, supplemental oxygen is also indicated ${ }^{13}$.

Exercise training or pulmonary rehabilitation aim to optimize performance of daily living activities and maximal exercise tolerance ${ }^{12}$. Mechanisms of lung functional improvement and exercise tolerance have not been fully established, but effects such as improved motivation, improved muscle function and biomechanics, desensibilization to dyspnea and increased aerobic capacity are evident ${ }^{11-14}$.

\section{Surgical Treatment}

Because medical therapy has been relatively ineffective in slowing the progression of emphysema, surgical attempts have occurred in the past, both to palliate and treat this disease. Early maneuvers included costochondrectomy and transverse sternotomy to improve thoracic mobility; other authors attempted to limit lung expansion with thoracoplasty and phrenectomy or elevate the diaphragm with pneumoperitoneum or abdominal constrictive belts ${ }^{1}$.

In the 1950's Otto Brantigan and Mueller ${ }^{2}$ speculated about the wedge excision of emphysematous patients thus decreasing the lung volume, leading patients to reduce dyspnea. This idea was based upon the concept that a smaller lung could restore the efficiency of the respiratory pump. Indeed, Brantigan's procedure did produce some clinical improvements in pulmonary function, but the mortality rate was high (18\%) and the procedure was soon abandoned. Thirty years later, Cooper ${ }^{1}$ and cols. revitalized this procedure with an operation known as lung volume reduction surgery or LVRS. This operation involved resection of $20 \%$ to $30 \%$ of hyperinflated lung that should be noncontributory to effective ventilation. The most affected portions were excised using a linear stapling device fitted with strips of bovine pericardium to buttress the stapled lines and eliminate air leakage through the stapled holes. Expected benefits were improvement in elastic recoil, lung compliance and chest wall conformation to reduce hyperinflation and allow resumption of a more normal diaphragmatic position. Improvement in ventilation-perfusion matching in the remaining lung tissue leading to better pulmonary function should occur as well. Their first report showed no early or late mortality related to the procedure. 
Initial studies reported significantly positive clinical results, which led LVRS to be performed by many surgeons worldwide. Short-term results from many nonrandomized studies have been reported. Most of them showed reduced hyperinflation and improved pulmonary function and also better ventilatory mechanics and exercise tolerance at 3 and 6 months after surgery. Because LVRS is a palliative, elective procedure, one of the major concerns was the related mortality rate ${ }^{15}$.

The selection process included marked hyperinflation of the chest and sufficient variation in the emphysema, to provide target areas accessible to lung resection. The degree of regional parenchymal destruction is better analyzed by computed tomography of the chest and distribution of function should be accessed by radionuclide ventilation-perfusion lung scanning. Thoracic distention is evaluated by chest radiography and lung volumes are determined by plethysmography. Although these selection criteria are somehow subjective, attempts have been made to identify objective patterns. Previous findings indicate that the morphologic character of emphysema plays a key role in the selection of candidates for LVRS. Visual scoring based on CT scan is less precise than quantitative analyses, however quicker and simpler for candidate selection. Patient selection criteria for lung volume reduction surgery are listed in table 1.

The operations used to treat emphysema included the excision of large bullae (bullectomy) and resection of emphysematous lung tissue. The latter procedure, our subject of interest, represents $20-30 \%$ of volume reduction in one or both lungs by means of stapler resection, laser application, or both. Acceptable results from stapler resection have been reported through a sternotomy, thoracotomy, clam shell incision and thoracoscopy. There have been some controversial results regarding the type of operation and whether this should be applied unilaterally or bilaterally ${ }^{16}$. The most extensive comparison of LVRS by median sternotomy (MS) or video assisted thoracic surgery (VATS) was published by the National Emphysema Treatment Trial (NETT) ${ }^{17}$. They analyzed 343 patients in the MS arm and 146 patients in the VATS arm and found that the two approaches carry similar risks of 30-day, 90-day and overall mortality. Although there was a slight trend for higher mortality after MS than VATS, this was not statistically significant. Both approaches determine similar changes in exercise capacity, lung function and disease specific quality of life, also showing significant improvement after 6 months. The mean hospital and physician costs for the LVRS admission were $\$ 8,207$ less for the VATS group compared to the MS group (95\% confidence interval[Cl]; $p=0.03$ ); mean total costs during the 6 months following surgery were $\$ 10,428$ lower for the VATS group ( $95 \% \mathrm{Cl}$ on difference; $p=0.005$ ). Costs analysis reflects fewer Intensive Care Unit stays and a reduced overall ength of stay for the VATS group. This important report concluded that choice of the approach is a matter of the surgeon's preference and experience.

Functional status before and after surgery is assessed by measuring multiple parameters of pulmonary function and quality of life indicators, but $\mathrm{FEV}_{1}$ is the most used as single indicator of functional status. Using this method, stapling is usually associated with more short-term (3-6 months) improvement than the laser technique. With regard to the staple line and comparisons of the type of buttressing (bovine pericardium or collagen), no significant differences have been found in the efficacy ${ }^{18,19,20}$.

Another controversial question is if LVRS should be attempted unilaterally or bilaterally. Unilateral LVRS should be performed intentionally in patients with distinct heterogeneity of emphysema between lungs identified and graded by radiologic findings, whereas simultaneous bilateral LVRS is preferred for patients with heterogeneous disease in both lungs but symmetrically distributed between the lungs. Spirometry, lung volumes and quality of life appeared to be superior for bilateral compared to unilateral LVRS, although there was no significant difference in mortality between the two methods ${ }^{21}$. Serna ${ }^{22}$ and colleagues found that survival at two years was better for bilateral than unilateral VATS LVRS. A recent study published by Pompeo ${ }^{23}$ and colleagues analyzed 97 patients with upperlobe prevailing emphysema by unilateral LVRS, and showed $82 \%$ of 5-year related survival.

There is an important question regarding the surgical technique: it has changed from an inverted $U$-shaped that goes from an anterior aspect of the upper lobe toward the apex and then down the back. The current technique is just a resection from the front, straight toward the back, removing almost all the upper lobe on the right. On the left, the portion of the upper lobe is removed almost completely, thus just the lingula is left intact ${ }^{1,21,22}$. Although this transverse resection is now preferred over oblique resection and it seems that there is no significant difference between both methods. This transition has been gradual, therefore there is no way to identify patients retrospectively with regard to the type of stapled line.

Irrespective of the method of choice, this operation is to be considered after maximal medical therapy has failed to produce satisfactory palliation and intended to return the emphysematous lung to an earlier stage in the natural history of obstructive lung disease.

\section{Discussion}

The American Thoracic Society has classified LVRS as an innovative rather than experimental procedure, however such a technique is surrounded by many unresolved questions. Until these questions are answered, LVRS cannot be considered a standard therapy. One of the major issues in LVRS is how to select appropriate candidates and how to assess and interpret results.

The current position of the American Thoracic Society is that LVRS should be performed only at centers where it can be completely studied through clinical trials and extensive physiologic evaluations. Appropriate candidates are those with severe emphysema refractory to medical therapy, disabling symptoms and evidence of air trapping $\left(\mathrm{FEV}_{1}<35 \%\right)$. Although patients who have $\mathrm{FEV}_{1}>40 \%$ are probably not sufficiently incapacitated for surgery, there is no consensus on a lower limit of $\mathrm{FEV}_{1}$ as an exclusion criterion for LVRS 24 . When the $\mathrm{FEV}_{1}$ is less than $30 \%$ of the predicted, $50 \%$ of patients will die within 3 to 4 years.

Many centers have patients over 75 years of age and significant associated illnesses, such as coronary artery disease or morbid obesity. Preoperative evaluation should comprise complete pulmonary and cardiac tests and other tests, such as dynamic MRIs, positron emission tomography scan and sleep studies could be used for screening. The distribution of emphysema is classified as heterogeneous or homogeneous based on the high-resolution computed tomography under a visual score system. The radiologist classifies the craniocaudal distribution of emphysema as predominantely affecting the upper lobes, predominantly affecting the lower lobes, diffuse or predominantly affecting the superior segments of the lower lobes; the latter three categories were classified as non-upper lobe emphysema. Before randomization eligible patients completed 6 to 10 weeks of pulmonary rehabilitation supervised by the transplant 
team. According to the NETT, patients with a $\mathrm{FEV}_{1} 20 \%$ or less and a either non-upper-lobe emphysema or a carbon monoxide diffusing capacity that was $20 \%$ or less of the predicted value, were determined to be at high risk of death after LVRS, with a low probability of functional benefit.

The National Emphysema Treatment Trial (NETT) was designed and supported by the National Heart Care and Financial Organization (Medicare and Medicaid Services) since January 1996, when Medicare stopped funding for this procedure. The NETT growth as a multicenter, randomized and large scale clinical trial to evaluate the effects of LVRS and to determine those who would and who would not benefit from this procedure. The main purposes were to compare medical to surgical therapy with respect to short and long term improvement in lung function and quality of life, to determine whether different surgical approaches (median sternotomy or VATS) are related to different outcomes and finally to evaluate costs associated to this procedure. Similar studies are being conducted in Massachusetts, Canada, and Great Britain.

The first NETT ${ }^{3}$ results examined 1033 patients and identified a group of 69 patients at a high risk of death compared with medical management in a group of patients with a low preoperative $\mathrm{FEV}_{1}$ and a uniform pattern of emphysema or low $D_{L c o}$. This report showed improved outcomes related to emphysema heterogeneity, upper versus lower lobe LVRS and bilateral versus unilateral LVRS.

In 2003, NETT reported the effects of LVRS versus medical therapy on survival and maximum exercise capacity in 1218 patients who were randomized for treatment between January 1998 and July 2002 and monitored for a mean of 2.4 years (figure 1 ). A subgroup of high risk patients $(n=140)$ - homogeneous pattern of emphysema on chest CT, $V E F_{1} \leq 20 \%$ and $D_{L C O} \leq 20 \%$ - also was analyzed (figure 2). The 90-day mortality rate in the surgery group was $7.9 \%$, higher than the medical therapy group $(p<0.001)$. Additional outcomes reported included pulmonary function, oxygen requirement, distance walked in 6 minutes, quality of life and respiratory symptoms. These data were updated in 2006, with a mean follow-up of 4.3 years.

The NETT studies concluded that lung volume reduction surgery increases the chance of improved exercise capacity, but does not confer a survival advantage over medical therapy. It does provide a survival advantage for patients with both predominantly upper-lobe emphysema and low baseline exercise capacity.

Meyers ${ }^{25}$ and cols. published results from a group of 20 patients with a $\mathrm{FEV}_{1}$ and diffusion capacity of carbon monoxide of $20 \%$ or less who underwent bilateral LVRS and showed a 90-day operative mortality of $5 \%$. In all patients the $\mathrm{FEV}_{1}$ increased from 0.46 (17\%) to 0.78 (32\%), a $73 \%$ change; the $D_{\text {Lco }}$ increased from $16 \%$ to $27 \%$, a $70 \%$ improvement and room air $\mathrm{PaO}_{2}$ increased from 55 $\mathrm{mmHg}$ to $64 \mathrm{mmHg}$. The Kaplan-Meier 5-year survivals did not differ between the high-risk and non-high-risk patients. He concluded that patients in this selected group might experience improvements in lung function, exercise tolerance and quality of life with acceptable morbidity and mortality after LVRS. Paradoxically this group achieved an improvement greater than in the rest of series, possibly explained by the larger target areas and lower $\mathrm{FEV}_{1}$.

It is indeed well established that these high-risk patients represent a relative contraindication to such procedure. The NETT ${ }^{3}$ reported two high risk groups randomized for surgical treatment: patients with low $\mathrm{FEV}_{1}$ and homogeneous distribution of emphysema and patients with very low $\mathrm{FEV}_{1}$ and a low $\mathrm{D}_{\mathrm{LCO}}$. The overall mortality in this group was $28.6 \%$ compared to $7.9 \%$ in the non-high-risk patients. These findings corroborate observations from early LVRS experience, and have added additional weight of evidence to the belief that these patients (homogeneous pattern of emphysematous destruction) are poor candidates. Also interesting in the NETT study, is the fact that the exercise capacity after 24 months had improved in $16 \%$ of patients in the surgery group as compared to $3 \%$ of patients in the medical group $(p<0.001)$. Among the 610 patients assigned to medical therapy, the 90-day mortality rate was 1.9\%, 33 (5.4\%) underwent LVRS outside the study and 15 (2.5\%) received lung transplantation during follow-up, may be related to worsening of lung function or lack of alternative therapy available. Miller and cols. ${ }^{26}$ published a recent study comparing LVRS to optimal medical therapy in two clinical trials and concluded that in carefully selected patients with advanced heterogeneous emphysema, quality of life had improved 6 to 12 months after LVRS combined with optimal medical therapy, results superior to those of patients who received optimal medical therapy only. Fishman and cols. ${ }^{9}$ concluded that patients with upper-lobe predominant emphysema and low exercise capacity had improved survival with LVRS, when compared to the medical therapy group and indicated two outcome predictors: distribution of emphysema and exercise capacity following pulmonary rehabilitation. Pulmonary rehabilitation provides substantial benefits for patients with severe COPD, including increased exercise capacity and decreased dyspnea. Although many patients never participate in this therapy modality, it is certainly less costly than surgery and associated with less immediate morbidity and mortality ${ }^{27}$.

Use of LVRS with undiagnosed pulmonary nodules and/or lung cancer is controversial and a wide range of abnormal tissue including adenocarcinoma, bronchoalveolar and carcinoids tumorlets has been found in lung resection following LVRS. De Rose ${ }^{28}$ and cols. advocate LVRS combined with nodule resection and reported recurrent lung cancer in 1 of 14 patients one year after operation by this technique. LVRS also has been performed with coronary artery bypass surgery, cardiac valvular and aortic aneurysm surgery.

Another controversial point is the mortality rate reported in some series; a few authors published hospital mortality, others operative mortality and others 30-day related mortality. Because significant mortality occurs between 30 and 90 days, it is established that 90 -day is the most useful indicator. A recent meta-analysis published by Berger $^{29}$ and colleagues showed similar 6 and 12 months mortality between LVRS and medical groups, after random assignment to treatment. It is well known that patients with predominantly upper-lobe have lower mortality and greater chance of improvement in exercise capacity than patients with non-upper lobe emphysema ${ }^{30,31}$.

LVRS has been employed adjunctively in these other special conditions:

1. resection for stage I lung cancer;

2. to wean ventilator dependent COPD patients;

3. to reduce unilateral hyperinflation of the native lung after single lung transplantation;

4. to serve not only as a bridge procedure but as an alternative for patients awaiting lung transplantation ${ }^{31}$.

\section{CONCLUSION}

The conclusion of this review is based upon the important benefits that LVRS can provide to patients under careful selection and rigorous preoperative and perioperative care. How long these benefits will last 
and who should be a candidate remains unclear. Further questions remain concerning the role of preoperative pulmonary rehabilitation, how LVRS improves lung function and survival also the impact of different surgical techniques on LVRS outcomes.

We optimistically await definitive data in the near future from the results of larger multicenter studies.

\section{Conflict of interest: None}

\section{Resumo}

\section{CiRURGia Redutora de Volume PULMONAR: UMA REVISÃo}

O objetivo deste estudo é revisar a literatura acerca da eficácia, segurança e viabilidade da cirurgia redutora de volume pulmonar (CRVP) em pacientes com enfisema pulmonar avançado. Estudos de CRVP de janeiro de 1995 a dezembro de 2009 foram incluídos através de pesquisa na Pubmed (MEDLINE) e Cochrane Library, na literatura inglesa. Palavras de busca tais como lung volume reduction surgery ou lung reduction surgery, pneumoplasty ou reduction pneumoplasty, COPD ou chronic obstructive pulmonary disease e surgery foram utilizadas. Também realizamos comparação entre terapia médica e cirúrgica. Os estudos analisados consistiram de randomizados controlados, estudos clínicos controlados, (randomizados e não randomizados), revisões e séries de casos. As questões acerca da validade através dos relatos iniciais, seguimentos incompletos, critérios de seleção indefinidos e análises de sobrevida confundiram a interpretação dos dados clínicos provenientes da CRVP. Pacientes com enfisema de predomínio em lobos superiores, inferiores e difuso, foram incluídos; também analisamos pontos chave, tais como morbidade e mortalidade peri-operatórias, assim como a medida da função pulmonar através do VEF 1. Enfisema do tipo bolhoso foi excluído desta revisão. Foram incluídas para análise também vias de acesso cirúrgico como esternotomia mediana, toracotomias unilateral ou bilateral e videotoracoscopia unilateral ou bilateral com grampeamento ou ablação por laser. Os resultados dos estudos prospectivos randomizados entre o tratamento clínico e a CRVP são essenciais para que alguma conclusão possa ser definitiva. [Rev Assoc Med Bras 2010; 56(6): 719-23]

UnITERMOS: Enfisema pulmonar. Cirurgia torácica. Cirurgia torácica vídeoassistida. Doença pulmonar obstrutiva crônica. Cirurgia vídeoassistida.

\section{REFERENCES}

1. Cooper JD, Patterson GA. Lung volume reduction surgery for emphysema. Chest Surg Clin North Am. 1995;5:815-31.

2. Brantigan OC, Mueller E. Surgical treatment of pulmonary emphysema. Am Surg. 1957;23:789-804.

3. National Emphysema Treatment Trial Research Group. A randomized trial comparing lung-volume reduction surgery with medical therapy for severe emphysema. N Engl J Med. 2003;348:2059-73.

4. Deslauriers J. A perspective on the role of surgery in chronic obstructive lung disease. Chest Surg Clin North Am.1995;5:815-31.

5. Sciurba FC, Rogers RM, Keenam RJ, Slivka WA, Gorcsan J $3^{\text {rd }}$, et al. Improvement in pulmonary function and elastic recoil after lung- reduction surgery for diffuse emphysema. N Engl J Med.1996;116:1095-9.

6. Rationale and design of the National Treatment Trial (NETT): a prospective randomized trial of lung volume reduction surgery. J Thorac Cardiovasc Surg. 1999;118:518-28.

7. Cassart M, Pettiaux N, Gevenois PA, Paiva, M, Estenne M. Effect of chronic hyperinflation on diaphragm length and surface area. Am J Resp Crit Care Med. 1997;156:504-8.
8. Murciano D, Ferretti, A, Boczkowski B, Sleiman C, Fournier, M, Millic-Emili J. Flow limitation and dynamic hyperinflation during exercise in COPD patients after lung transplantation. Chest. 2000;118:1248-54.

9. Fishman A, Martinez F, Naunheim K, Piantadosi S, Wise R, Ries A, et al. A randomized trail comparing lung-volume reduction surgery with medical therapy for severe emphysema. N Engl J Med. 2003;348:2059-73.

10. L.M. Fabbri, S.S. Hurd, for the GOLD Scientific Committee Global Strategy for the Diagnosis, Management and Prevention of COPD: 2003 update. Eur Respir J. 2003;22:1-2.

11. Celli BR, Mac Nee W. Standards for the diagnosis and treatment of patients with COPD: a summary of the ATS/ERS position paper. Eur Respir J. 2004;23:932-46.

12. Sutherland ER, Cherniack RM. Management of chronic obstructive pulmonary disease. N Engl J Med. 2004;350:2589-97.

13. Terziyski KV, Marinov BI, Aliman OI, St Kostianev S. Oxygen uptake efficiency slope and chronotropic incompetence in chronic heart failure and chronic obstructive pulmonary disease. Folia Med. 2008;50:39-47.

14. Gademan MG, Swenne CA, Verwey HF, van de Vooren H, Haest JC, van Exel HJ, Lucas CM, Cleuren GV, Schalij MJ, van der Wall EE. Exercise training increases oxygen uptake efficiency slope in chronic heartfailure. Eur J Cardiovasc Prev Rehabil. 2008; 15:140-4.

15. Flaherty KR, Kazerooni EA, Curtis JL, lannettoni M, Lange L, Schork MA, et al. Short-term an dlong-term outcomes after lung volume reduction surgery: prediction by quantitative CT. Chest. 2001;119:1337-46

16. Stirling GR, Babidge WJ, Peacock MJ, Smith JA, Matar KS, Snell G. et al. Lung volume reduction surgery in emphysema: a systematic review. Ann Thorac Surg. 2001;72:641-8.

17. National Emphysema Treatment Trial Research Group. Safety and efficacy of median sternotomy versus video-assisted thoracic surgery for lung volume reduction surgery. J Thorac Cardiovasc Surg. 2004;127:1350-60.

18. Fein AM. Lung volume reduction surgery: aswering the ecrucial questions. Chest. 1998;113(Suppl):277S-82S.

19. Santambrogio L, Nosotti M, Baisi A, Bellaviti N, Pavoni G, Rosso L. Buttressing staple lines with bovine pericardium in lung resection for bullous emphysema. Scand. Cardiovasc. J.1998;32:297-9.

20. Stammberger U, Klepetko W, Stamatis G, Hamacher J, Schmid RA, Wisser W, et al. Buttressing the staple line in lung volume reduction surgery: a randomized three-center study. Ann Thorac Surg 2000;70:1820-5.

21. Serna DL, Brenner M, Osann KE, McKenna RJ, Chen JC, Fischel RJ, et al. Survival after unilateral versus bilateral lung volume reduction surgery for emphysema. J Thorac Cardiovasc Surg. 1999;118:1101-9.

22. McKenna RJ, Brenner M, Fischel RJ, Gelb AF. Should lung volume reduction for emphysema be unilateral or bilateral? J Thorac Cardiovasc Surg. 1996;112:1331-9.

23. Pompeo E, Mineo TC, for the Pulmonary Emphysema Research Group. Long-term outcome of staged versus one-stage bilateral thoracoscopic reduction pneumoplasty. Eur J Cardiothorac Surg.2002;21:627-33.

24. The American Society for Transplant Physicians (ASTP)/American Thoracic Society (ATS)/European Respiratory Society (ERS)/International Society for Heart and Lung Transplantation (ISHLT). International guidelines for the selection of lung transplant candidates. Am J Respir Crit Care Med. 1998;158:335-9.

25. Meyers BF, Yusen RD, Guthrie TJ, Davis G, Pohl MS, Lefrak SS, et al. Outcome of bilateral lung volume reduction in patients with emphysema potentially eligible for lung transplantation. J Thorac Cardiovasc. Surg. 2001;122:10-7.

26. Miller J, Lee R, Mansour KA. Lung volume reduction surgery: lessons learned. Ann Thorac Surg. 1996;61:1464-9.

27. Wise RA, Drummond MB. The Role of NETT in Emphysema Research Proceedings of the ATS. Proc Am Thorac Soc. 2008;5:385-92.

28. Allen G, DeRose J Jr. Pulmonary nodule resection during lung volume reduction surgery. AORN J. 1997;66:808-18.

29. Miller JD, Berger RL, Malthaner RA, Celli BR, Goldsmith $\mathrm{CH}$, Ingenito EP, et al. Lung volume reduction surgery vs medical treatment for patients with advanced emphysema. Chest. 2005;127:1166-77.

30. Naunheim K. Lung-volume reduction surgery: a vanishing operation? J Thorac Cardiovasc Surg. 2007;133:1412-3.

31. Boasquevisque CHR, Yildirim E, Waddel1 TK, Keshavjee S. Surgical techniques: lung transplant and lung volume reduction. Proc Am Thorac Soc. 2009;6:66-78.

32. Reilly J, Washko G, Pinto-Plata V, Velez E, Kenney L, Berger R, et al. Biological lung volume reduction surgery. A new bronchoscopic therapy for advanced emphysema. Chest. 2007;131:1108-13.

33. Ingenito, EP; Wood, DE; Utz, JP. Bronchoscopic lung volume reduction in severe emphysema. Proc Am Thorac Soc. 2008;5:454-60. 